\title{
Highly Branched Sn-Doped ZnO Nanostructures for Sunlight Driven Photocatalytic Reactions
}

\author{
Yangyang Liu, Xiaodong Chen, Ying Xu, Quanhua Zhang, and Xianying Wang \\ School of Materials Science and Engineering, University of Shanghai for Science and Technology, Shanghai 200093, China \\ Correspondence should be addressed to Xianying Wang; xianyingwang@usst.edu.cn
}

Received 17 June 2014; Revised 16 July 2014; Accepted 7 August 2014; Published 11 December 2014

Academic Editor: Shaowen Cao

Copyright (C) 2014 Yangyang Liu et al. This is an open access article distributed under the Creative Commons Attribution License, which permits unrestricted use, distribution, and reproduction in any medium, provided the original work is properly cited.

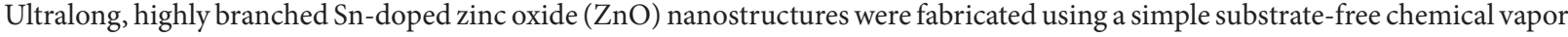
deposition (CVD) method. The nanostructures exhibited efficient photocatalytic activities in degradation of methylene blue (MB) under natural sunlight. $100 \%$ of $\mathrm{MB}$ with the concentration of $10 \mathrm{mg} / \mathrm{L}$ could be completely removed within 36 minutes. Possible reasons for the enhanced photocatalytic effect were analyzed.
\end{abstract}

\section{Introduction}

Energy and environment issues are two severe problems we face today. Utilizing solar energy is considered as one of the major strategies to solve the energy and environmental problems. Photocatalytic effect is a perfect interpretation, which can complete renewable energy generation and environmental remediation without any harmful materials. However, there are two major drawbacks for traditional photocatalytic materials. First, the recombination of photogenerated electrons and holes is too fast, which results in low quantum efficiencies and limits the photocatalytic potentials. Second, the utilization of solar energy is limited, which greatly hinders the commercialization of such technology. Great efforts have been made to overcome these two issues. Cocatalysts such as noble metals [1, 2], grapheme [3], and semiconducting quantum dots [4] have been proved to be effective in reducing the probability of carrier recombination. In order to expand the band of solar energy adsorption, we can either tune the bandgaps of semiconducting photocatalysts or use composite photocatalytic materials $[5,6]$. On the other hand, to increase the effective areas for solar energy absorption and photocatalytic reaction, the surface areas of the photcatalysts are expected to be as large as possible.

Among all the photocatalysts, $\mathrm{ZnO}$ is considered to be very competitive due to its nontoxic nature, low cost, high reactivity, and good conductivity. Moreover, onedimensional $\mathrm{ZnO}$ nanostructures have the most abundant morphologies; thus the surface to volume ratio $(S / V)$ can be tuned in a wind range. $\mathrm{ZnO}$ hollow structures [7], nanoflowers [8], and nanosheets [9] are proved to have enhanced photocatalytic efficiency than $\mathrm{ZnO}$ nanoparticles due to the large $S / V$. On the other hand, doping $\mathrm{ZnO}$ with other elements such as $\mathrm{Sn}, \mathrm{Al}$, and $\mathrm{Ti}$ has been proved to be effective in adjusting the bandgap, resulting in enhanced light adsorption in the visible wavelength range [10-12].

In this work we report a simple substrate-free, catalyst free, high-yield growth method for fabricating highly branched $\mathrm{Sn}$-doped $\mathrm{ZnO}$ nanostructures. The products can be synthesized in large scale if only the precursors are sufficient. The $\mathrm{ZnO}$ nanostructures exhibited excellent photocatalytic activities in the degradation of methylene blue (MB) in aqueous solution under natural sunlight irradiation. The superior photocatalytic behaviors can be attributed to the combined effects of large $S / V$, abundant surface defects, and enhanced visible light adsorption. Scanning electron microscope (SEM) was used to characterize the morphologies. Photoluminescence (PL), Raman, and X-ray diffraction (XRD) were carried out to examine the defects and crystal structures.

\section{Experimental}

2.1. Synthesis of Sn-Doped $\mathrm{ZnO}$ Nanostructures. Sn-doped $\mathrm{ZnO}$ nanostructures were synthesized using a single-tube 
chemical vapor transporting and condensation system equipped with Lindberg blue furnace. The diameter of the tube is $2.54 \mathrm{~cm}$ and the length is $65 \mathrm{~cm}$. Prior to nanostructure growth, the temperature inside the furnace was carefully calibrated using a K-type thermocouple (TES 1310, Taiwan). Zinc oxide (Alfa Aesar 99.99\%) and tin oxide (Alfa Aesar, $100 \%)$ mixed with equal amount of graphite (200 mesh, Alfa Aesar 99.99\%) were calibrated using a K-type thermocouple (TES 1310, Taiwan). Zinc oxide (Alfa Aesar 99.99\%) and tin oxide (Alfa Aesar, 100\%) mixed with equal amount of graphite (200 mesh, Alfa Aesar 99.99\%) powers were placed in a quartz tube with appropriate position directly which was positioned in the furnace during growth. The weight ratio of $\mathrm{ZnO}$ and $\mathrm{SnO}_{2}$ precursors is kept at 95\%:5\%. High purity argon (Ar, $99.999+\%)$ and oxygen $\left(\mathrm{O}_{2}, 99.999+\%\right)$ with different ratios were used as the carrier gas at a constant total flow rate of $50 \mathrm{sccm}$. During the experiment, the targeted temperature of the inside of the furnace was $900^{\circ} \mathrm{C}$ with heating rate $30^{\circ} \mathrm{C} /$ minute, and the holding time was 25 minutes for all the samples under environmental conditions.

2.2. Sample Characterization. The morphologies of the samples were characterized using a field-emission SEM (FESEM, FEI, Quanta FEG). The crystal structures of as-prepared sample were tested using X-ray diffraction (XRD, Brukers, D8 Advance). Room temperature PL spectra were collected using FS 920 type spectrometer (Edinburgh) at the exciting wavelength of $325 \mathrm{~nm}$. Raman spectra of $\mathrm{ZnO}$ nanostructure were examined using Raman station $400 \mathrm{~F}$ machines (PerkinElmer). The light absorbance spectra were obtained by spectrometer with UV-Vis-2550.

2.3. Photocatalytic Reactions. The photocatalytic activities of samples were examined using methylene blue (MB) as the indicator. Different weights of Sn-doped $\mathrm{ZnO}$ photocatalysts were added into a bottle containing $40 \mathrm{mg} \mathrm{MB}$ aqueous solution with the concentration of $10 \mathrm{mg} / \mathrm{L}$. Then the photocatalysts were magnetically stirred in the dark for 30 minutes to reach adsorption-desorption balance. The photodegradation experiments were carried out under natural sunlight (the power intensity was measured to be $1.8 \mathrm{~mW} / \mathrm{cm}^{2}$ ). The solutions were sampled at intervals of 6 minutes and centrifuged at $8000 \mathrm{rpm}$, then analyzed by recording variations in the absorption band $(664 \mathrm{~nm})$ in the $\mathrm{UV}-\mathrm{Vis}$ spectra of MB using UV-Vis-2550.

\section{Results and Discussions}

The growth process of $\mathrm{Sn}$-doped $\mathrm{ZnO}$ branched wires is schematically illustrated in Figure 1(a). According to thermal analysis results (see Figure S1 in Supplementary Material available online at http://dx.doi.org/10.1155/2014/381819), Sn will be evaporated at a relatively low temperature. The Sn vapor condensed at the surface of the precursor powders. Because of the low melting point of $\mathrm{Sn}$ metal, droplet will form at the surface of the powers, which will serve as the active sites for the subsequent $\mathrm{Zn}$ vapor deposition. Therefore the growth is a substrate-free self-catalyzed process, which is cost-effective and suitable for large scale production. Figures 1(b) and 1(c) show the low magnification and high magnification SEM images of the as-synthesized samples. From Figure 1(b), it can be seen that the wires are extremely long with highly branched nanorods. The length of the stem is up to several millimeters which can be obtained from optical microscope image inset of the Figure 1(b). The lengths and the width branched nanorods are in the range of 5$10 \mathrm{um}$ and $0.4-0.8 \mathrm{um}$, respectively. From the XRD pattern in Figure 1(d), it is obvious that the sample has typical wurtzite crystal structures with four characteristic peaks. The strong peaks located at $32.28^{\circ}, 34.96^{\circ}, 36.62^{\circ}$, and $57.03^{\circ}$ are corresponding to the miller index of (100), (002), (101), and (110) phases of $\mathrm{ZnO}$. No peaks related with $\mathrm{SnO}_{2}$ were detected, demonstrating that the $\mathrm{Sn}$ atoms were completely dissolved in the $\mathrm{ZnO}$ lattices.

Figure 2 summarized the optical properties of the Sndoped $\mathrm{ZnO}$ nanostructures. For comparisons, pure $\mathrm{ZnO}$ were also measured. Figure 2(a) is the Raman spectra of Sn-doped $\mathrm{ZnO}$ and undoped $\mathrm{ZnO}$ nanowires. Wurtzite $\mathrm{ZnO}$ belongs to P63 mc space group and crystal symmetry is C6V4. The center of the Brilliion is $\Gamma_{\text {opt }}=A_{1}+2 B_{1}+E_{1}+2 E_{2}$, where $A_{1}, E_{1}$ are polarity mode which is infrared and Raman active, $E_{2}$ is nonpolar and Raman active only, $B_{1}$ is static with nothing. $333 \mathrm{~cm}^{-1}, 383 \mathrm{~cm}^{-1}, 438 \mathrm{~cm}^{-1}, 577 \mathrm{~cm}^{-1}$, and $1151 \mathrm{~cm}^{-1}$ can be attributed to $2 E_{2}, A_{1}$ (TO), $E_{2}$ (high), $A_{1}$ (LO), and $2 E_{1}$ (LO) mode, respectively. The strongest peak at $438 \mathrm{~cm}^{-1}$ was usually associated with crystalline quality and the peaks at $383 \mathrm{~cm}^{-1}$ and $577 \mathrm{~cm}^{-1}$ usually correspond to oxygen deficiency. It can be seen that the increase in visible emission intensity for the $\mathrm{Sn}$-doped $\mathrm{ZnO}$ compared with that of the pure could be attributed to intrinsic defects, which are created only when $\mathrm{Sn}$ diffused in the $\mathrm{ZnO}$ host matrix. The photoluminescence spectra of as-prepared Sndoped $\mathrm{ZnO}$ nanostructures and undoped samples are shown in Figure 2(b). While undoped $\mathrm{ZnO}$ nanowires only show strong intrinsic emission, Sn-doped sample has significant visible peak centered at $500 \mathrm{~nm}$, which can be attributed to the defect related emission. The light emission in the visible range demonstrates the formation of the many intermediate energy levels in the bandgaps of $\mathrm{ZnO}$. The defects may contribute to the photocatalytic efficiency in two ways. First, the decrease of bandgap will facilitate the visible light absorption. Second, surface oxygen deficiencies can serve as electron capture centers, which could reduce the recombination rate of photogenerated electrons and holes. Otherwise, their UV emission broadens towards longer wavelengths which could be attributed to the decrease of the bandgap when $\mathrm{ZnO}$ is doped Sn. We believe that luminescence of the Sn-doped $\mathrm{ZnO}$ is related not only to intrinsic defects but also to the nature of $\mathrm{Sn}$ ions present in the $\mathrm{ZnO}$ host lattice, which need further study. The optical absorption characters of the samples were examined using UV-Vis diffuse reflectance spectrum, as is shown in Figure 2(c). Obviously, the samples show significant adsorption in the visible range compared with pure $\mathrm{ZnO}$ [13] and commercial $\mathrm{TiO}_{2}$ [14], which is related with the reduced bandgap width caused by $\mathrm{Sn}$ doped. Figure 2(d) shows the transient photocurrent response of the samples. It 


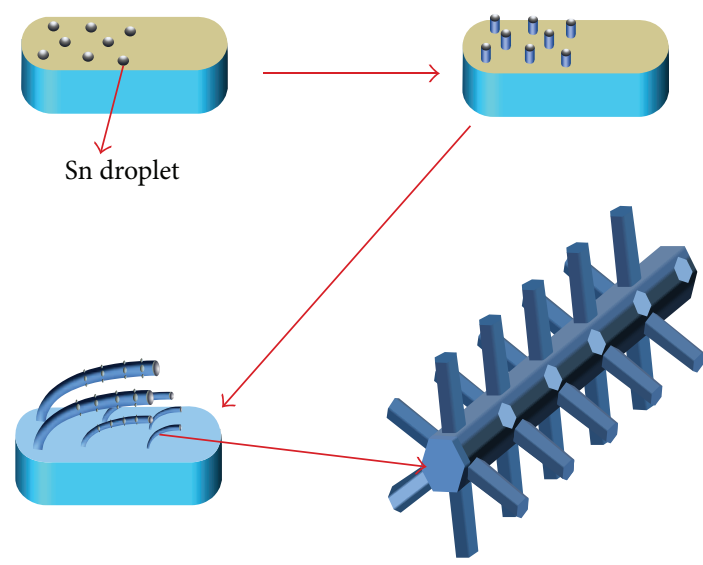

(a)

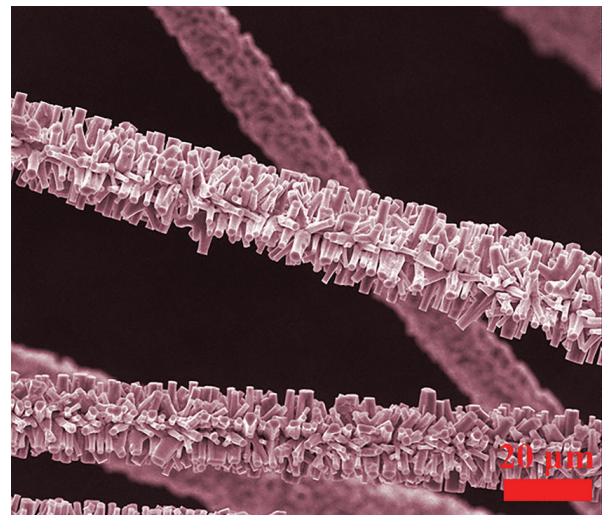

(c)

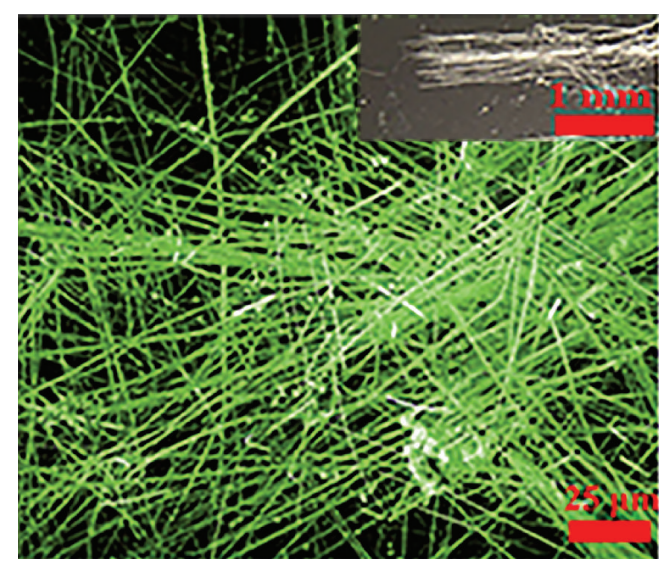

(b)

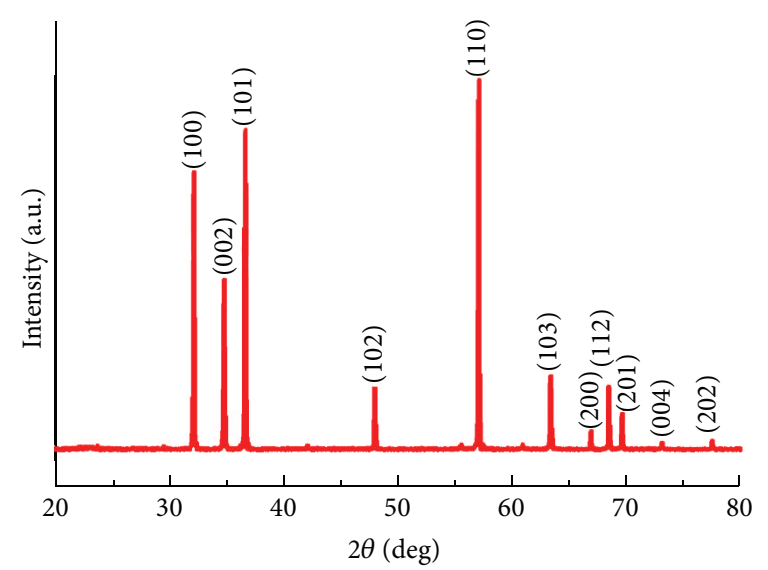

(d)

FIGURE 1: Morphologies and structures of as-synthesized samples. (a) Schematic diagram of the growth process. (b) Low-magnification SEM image. Inset: optical microscope image of the aligned samples. (c) High-magnification SEM image. (d) XRD pattern.

can be seen that the photocurrent increased eight times under the irradiation of sunlight. The photocurrent was greatly improved compared with undoped $\mathrm{ZnO}$, indicating that the charge separation rate was enhanced.

The photocatalytic activity of these $\mathrm{ZnO}$ nanostructures was examined using methylthionine chloride (MB) as the indicator. Natural sunlight was used as the light source. The reaction process is monitored spectrophotometrically by measuring the degradation of $\mathrm{MB}$, which exhibits a distinct spectral profile with an adsorption maximum at $664 \mathrm{~nm}$. From Figure 3(a), it is clear that the concentration of $\mathrm{MB}$ decreases dramatically while catalyzed using $\mathrm{Sn}$-doped $\mathrm{ZnO}$ nanostructures. $60 \%$ of the $\mathrm{MB}$ dyes can be decomposed in 6 minutes. The $\mathrm{MB}$ dyes can be completely removed in 36 minutes. In comparison, the photocatalytic efficiency of undoped $\mathrm{ZnO}$ is obviously lower. In 36 minutes, only $60 \%$ of $\mathrm{MB}$ can be decomposed. The $C / C_{0}$ curves as a function of time were plotted in Figure 3(c), both pure $\mathrm{ZnO}$ and the $\mathrm{Sn}$-doped $\mathrm{ZnO}$ photocatalysts can effectively remove the MB. Moreover, the Sn-doped $\mathrm{ZnO}$ catalysts exhibit higher photocatalytic activity compared with pure $\mathrm{ZnO}$. The kinetic curve shows linear relationships with time and can be fitted using the kinetic equation $\ln \left(C / C_{0}\right)=-k t$, demonstrating that the photodegradation reaction of $\mathrm{MB}$ can be considered as a pseudo-first-order reaction. Kinetic value is an important parameter for the photocatalyst. Figure 3(c) shows the bar graph of rate constants which could reach $0.11 \mathrm{~min}^{-1}$ when catalyzed by $\mathrm{Sn}$-doped $\mathrm{ZnO}$, which is almost 4 times higher than that of pure $\mathrm{ZnO}$. Also, it is much higher than the values reported in the literatures [15-18], suggesting that Sn-doped branched nanowires have superior photocatalytic effects.

The superior photocatalytic efficiency of Sn-doped $\mathrm{ZnO}$ branched nanostructures can be schematically illustrated in Figure 4 . When the photocatalysts were irradiated by sunlight with the photon energy $h \gamma$ that matched or exceeded the bandgap energy $(\mathrm{Eg})$ of $\mathrm{ZnO}(3.37 \mathrm{eV})$, electrons could be excited from the valence band (VB) to the conductions band (CB), simultaneously leaving the same number of holes behind in the VB. The holes and electrons would react with $\mathrm{H}_{2} \mathrm{O}$ and oxygen dissolved in water which were adsorbed at the surface of $\mathrm{ZnO}$ nanostructures and generated hydroxyl radicals $\left({ }^{\circ} \mathrm{OH}\right)$ and superoxide anions radicals $\left(\mathrm{O}_{2}{ }^{-}\right)$, respectively, with extremely high oxidation properties. These $\mathrm{OH}$ radicals and superoxide anion radicals could decompose $\mathrm{MB}$ 


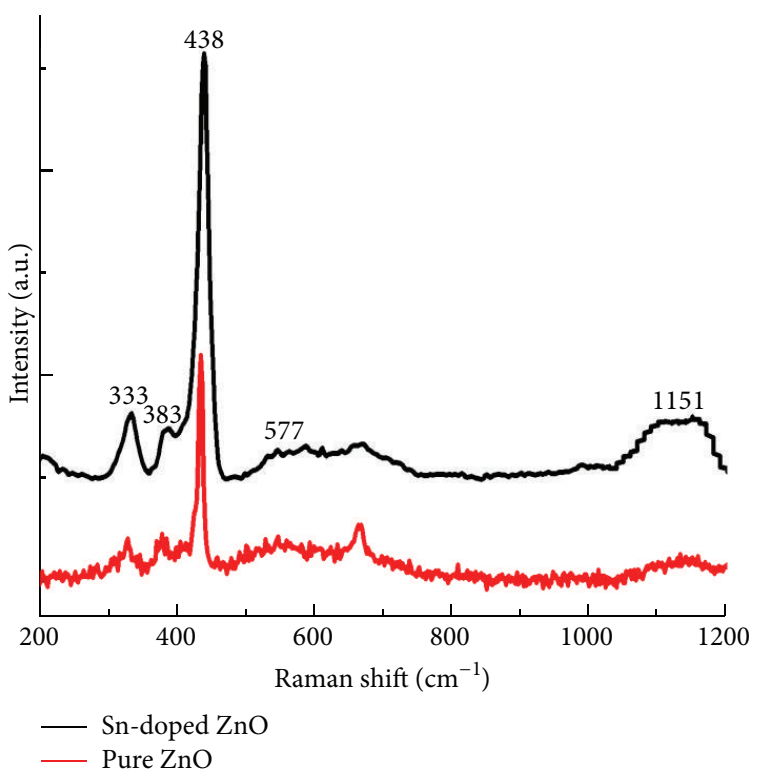

(a)

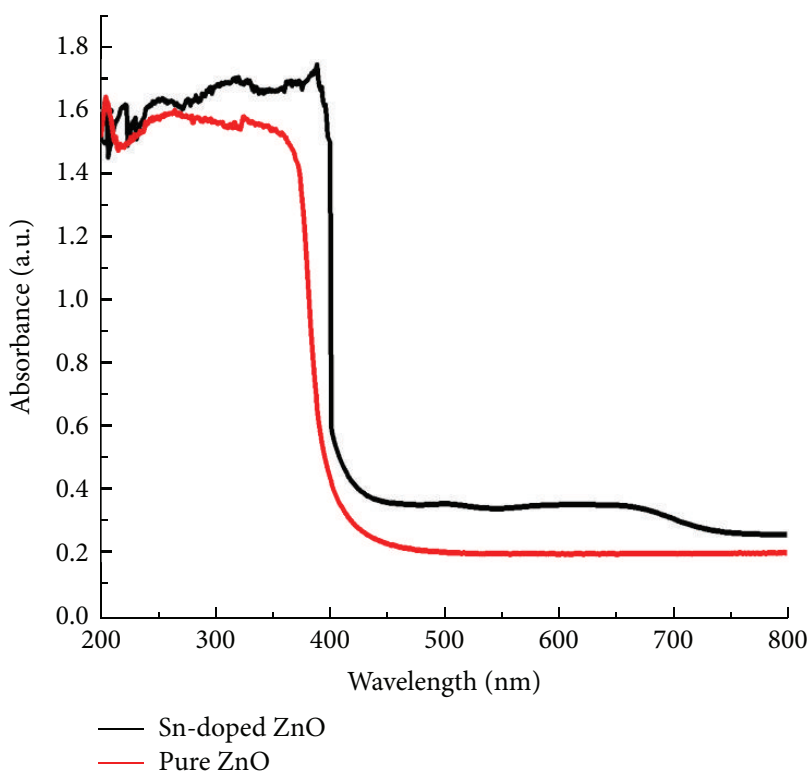

(c)

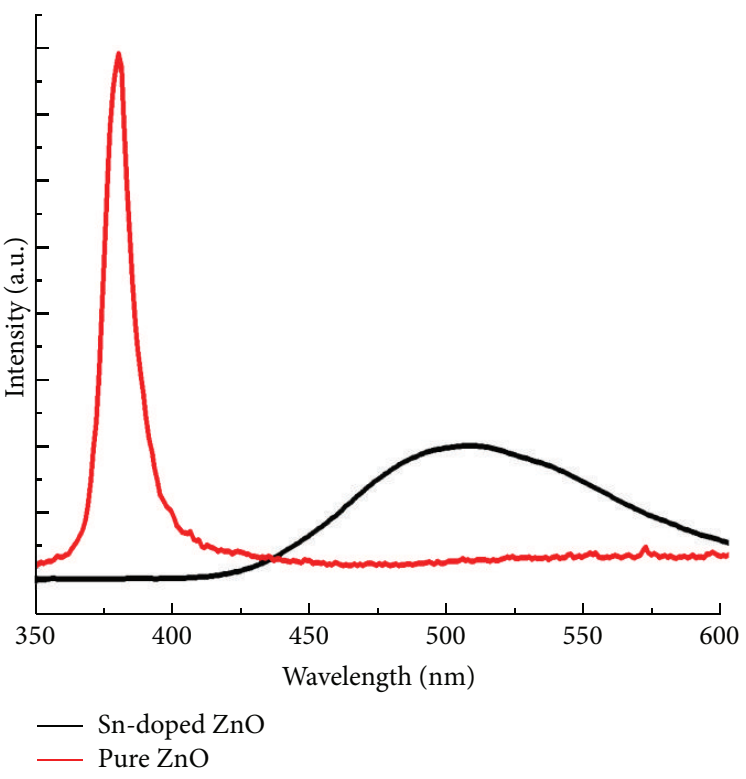

(b)

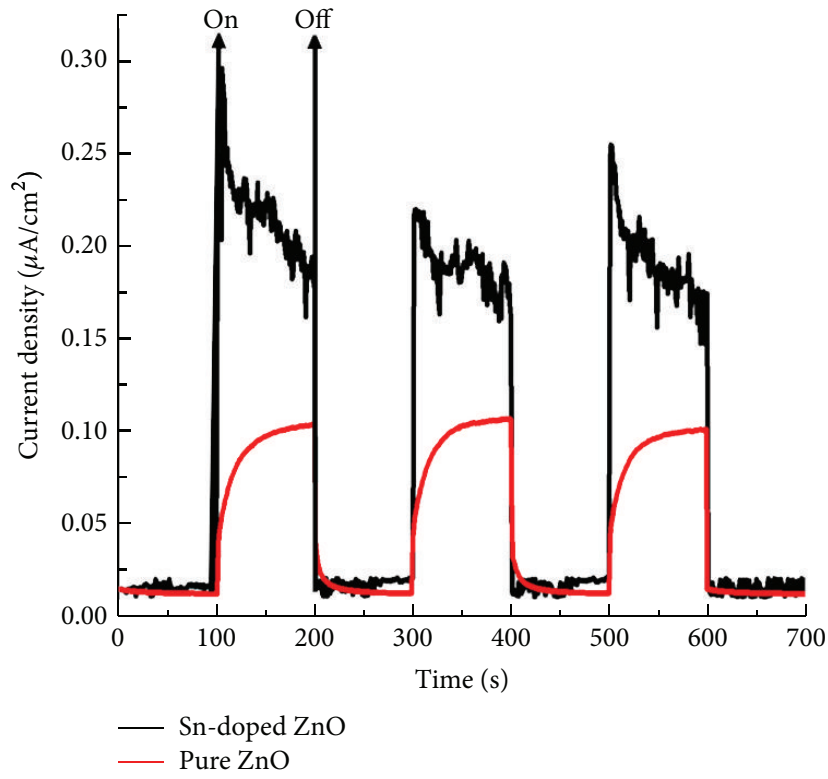

(d)

FIGURE 2: (a) Raman spectra. (b) PL spectra. (c) UV-Vis absorbance curve. (d) Transient photocurrent response of as-synthesized samples and pure $\mathrm{ZnO}$.

dye into dioxide and water, resulting in the mineralization of organic dyes in the aqueous solution. The superior photocatalytic activity of $\mathrm{Sn}$-doped $\mathrm{ZnO}$ branched wires must be related with their unique morphologies and abundant surface defect states. Branched $\mathrm{ZnO}$ nanostructures have large $S / V$, which could facilitate the light adsorption, increase the concentration of photo generated carriers, and enlarge the effective area of photodegradation reaction. Countless branches of the microwires will significantly decrease the light reflection and enhance the sunlight utilization rate. Besides, surface defects of the samples were also considered to be a critical factor for enhancing photocatalytic activity. A bunch of defects states were formed during the synthesis of $\mathrm{ZnO}$ nanostructures, which was confirmed by PL spectra (Figure 2(b)) and Raman spectra (Figure 2(a)). These defects could trap photogenerated holes by forming shallow levels and therefore the recombination probability of electrons and holes could greatly be restrained. On the other hand, surface defects will cause many intermediate energy levels in the bandgaps of $\mathrm{ZnO}$, which will enhance the light adsorption in the visible range (Figures 4 and $2(c))$. Therefore the photocatalytic efficiency could be greatly improved. The band structure in Figure 4 illustrates that many intermediate energy formed because of the deficiency 


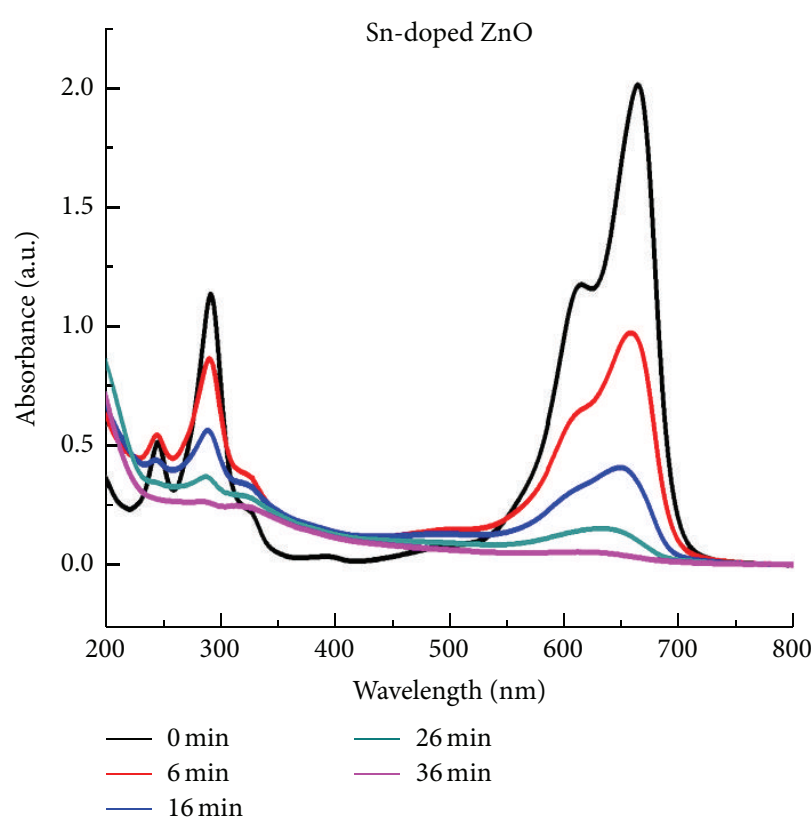

(a)

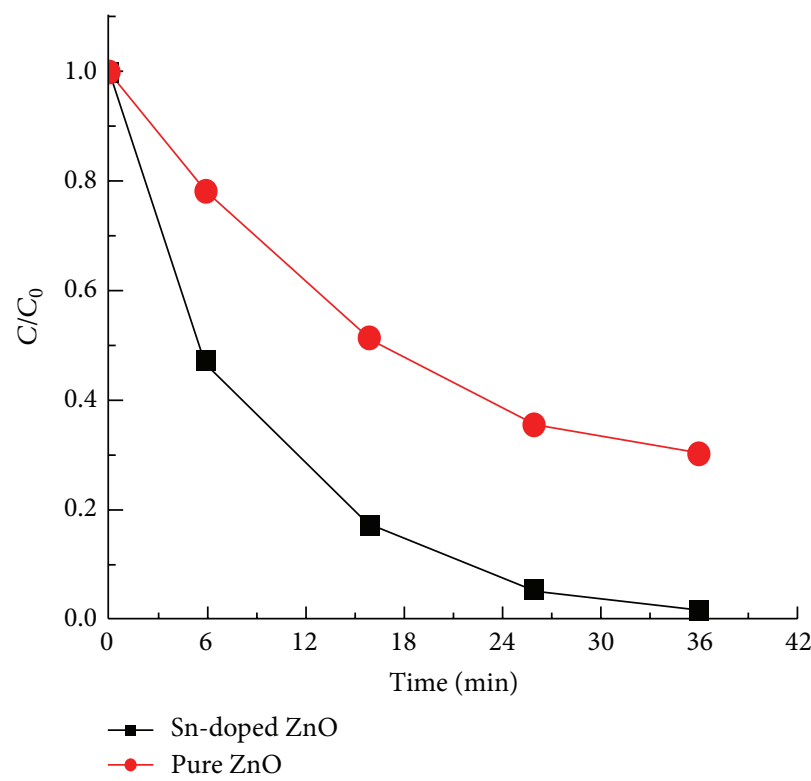

(c)

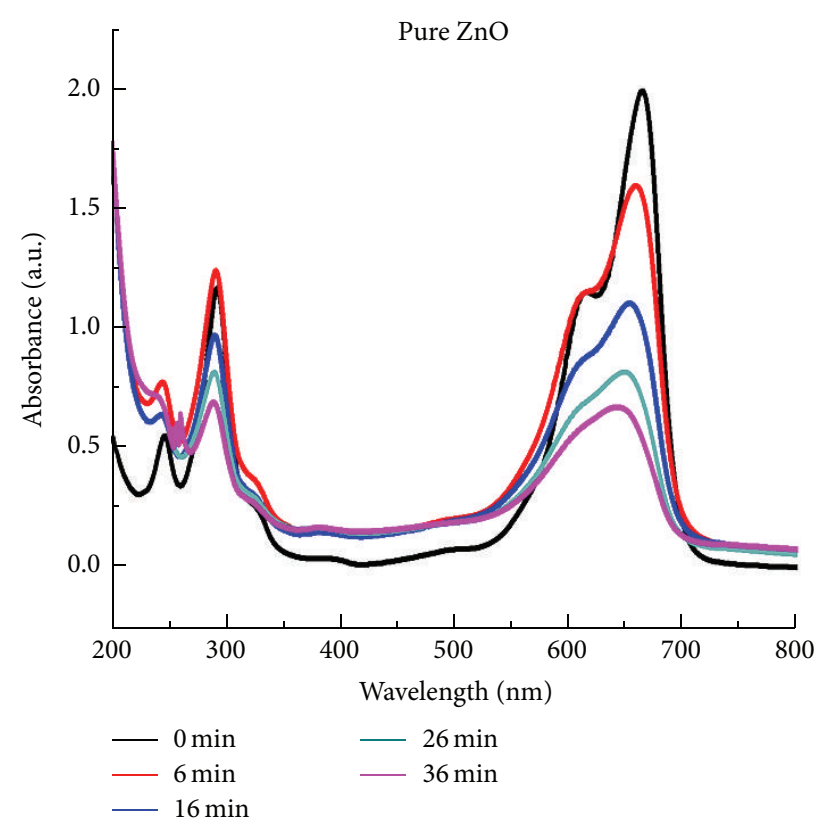

(b)

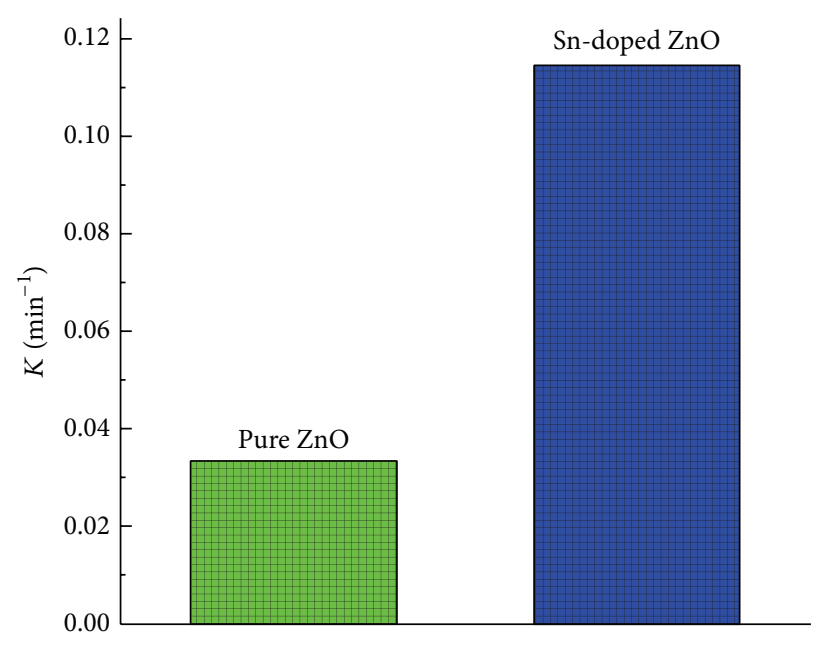

(d)

FIGURE 3: (a)-(b) Absorption spectra of MB solution at different time after irradiating under the natural solar light using Sn-doped $\mathrm{ZnO}$ nanostruatures and pure $\mathrm{ZnO}$ as the photocatalyst. (c) The $C / C_{0}$ versus time curves of $\mathrm{MB}$. (d) Rate constants of Sn-doped and pure $\mathrm{ZnO}$ photocatalyst.

which will significantly increase the light absorption in the visible range.

\section{Conclusions}

In summary, Sn-doped $\mathrm{ZnO}$ nanostructures were successfully synthesized using simple, substrate-free, and catalystfree CVD method. The nanostructures are highly branched and have abundant surface defects, which are desirable for the application of photocatalysts. Photocatalytic performances of these nanostructures were evaluated using $\mathrm{MB}$ solution as the indicator under the natural sunlight. The results demonstrated that the photocatalysts are very efficient. $100 \% \mathrm{MB}$ was discomposed in 36 minutes. The superior photocatalytic behavior can be attributed to the synergetic effect of large $S / V$ and rich surface oxygen states. Our research provided a simple yet efficient way to fabricate $\mathrm{ZnO}$ based photocatalysts in large scale. Also, the "superlong" nature of Sn-doped $\mathrm{ZnO}$ nanostructures suggests that the photocatalysts are recyclable, which is also critical for the commercial use. 


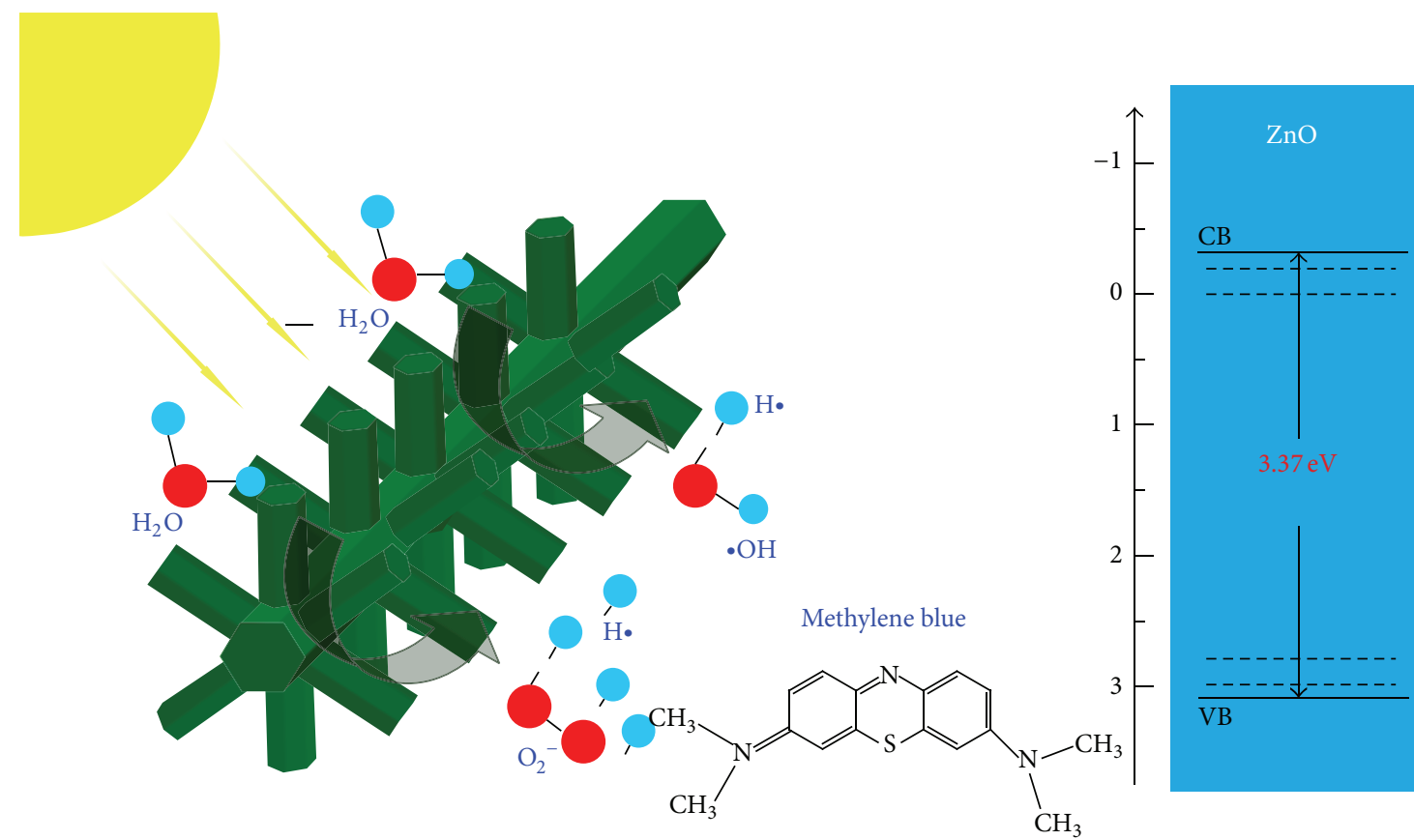

FIGURE 4: Schematic diagram of photocatalytic mechanism of ultralong Sn-doped ZnO nanostructures.

\section{Conflict of Interests}

The authors declare that there is no conflict of interests regarding the publication of this paper.

\section{Acknowledgments}

This work was supported by the Natural Science Foundation of China (51072119), Innovation Program of Shanghai Municipal Education Commission (12ZZ139), the Key Project of Chinese Ministry of Education (12057), and the Hujiang Foundation of China (B14006).

\section{References}

[1] J. Zhang, J. Yu, M. Jaroniec, and J. R. Gong, "Noble metalfree reduced graphene oxide- $\mathrm{Zn}_{x} \mathrm{Cd}_{1-x} \mathrm{~S}$ nanocomposite with enhanced solar photocatalytic $\mathrm{H}_{2}$-production performance," Nano Letters, vol. 12, no. 9, pp. 4584-4589, 2012.

[2] V. Subramanian, E. E. Wolf, and P. V. Kamat, "Catalysis with $\mathrm{TiO}_{2} /$ gold nanocomposites. Effect of metal particle size on the fermi level equilibration," Journal of the American Chemical Society, vol. 126, no. 15, pp. 4943-4950, 2004.

[3] Q. J. Xiang, J. G. Yu, and M. Jaroniec, "Synergetic effect of $\mathrm{MoS}_{2}$ and graphene as cocatalysts for enhanced photocatalytic $\mathrm{H}_{2}$ production activity of $\mathrm{TiO}_{2}$ nanoparticles," Journal of the American Chemical Society, vol. 134, no. 15, pp. 6575-6578, 2012.

[4] J. Zhao, M. A. Holmes, and F. E. Osterloh, "Quantum confinement controls photocatalysis: a free energy analysis for photocatalytic proton reduction at CdSe nanocrystals," ACS Nano, vol. 7, no. 5, pp. 4316-4325, 2013.

[5] S. Khanchandani, S. Kundu, A. Patra, and A. K. Ganguli, "Band gap tuning of $\mathrm{ZnO} / \mathrm{In}_{2} \mathrm{~S}_{3}$ core/shell nanorod arrays for enhanced visible-light-driven photocatalysis," Journal of Physical Chemistry C, vol. 117, no. 11, pp. 5558-5567, 2013.

[6] G. Dai, J. Yu, and G. Liu, "Synthesis and enhanced visible-light photoelectrocatalytic activity of p-n junction $\mathrm{BiOI} / \mathrm{TiO}_{2}$ nanotube arrays," Journal of Physical Chemistry C, vol. 115, no. 15, pp. 7339-7346, 2011.

[7] J. Yin, Q. Lu, Z. Yu, J. Wang, H. Pang, and F. Gao, "Hierarchical $\mathrm{ZnO}$ nanorod-assembled hollow superstructures for catalytic and photoluminescence applications," Crystal Growth and Design, vol. 10, no. 1, pp. 40-43, 2010.

[8] F. Barka-Bouaifel, B. Sieber, N. Bezzi et al., "Synthesis and photocatalytic activity of iodine-doped $\mathrm{ZnO}$ nanoflowers," Journal of Materials Chemistry, vol. 21, no. 29, pp. 10982-10989, 2011.

[9] J.-Y. Dong, C.-H. Lin, Y.-J. Hsu, S.-Y. Lu, and D. S.-H. Wong, "Single-crystalline mesoporous $\mathrm{ZnO}$ nanosheets prepared with a green antisolvent method exhibiting excellent photocatalytic efficiencies," CrystEngComm, vol. 14, no. 14, pp. 4732-4737, 2012.

[10] J.-H. Sun, S.-Y. Dong, J.-L. Feng, X.-J. Yin, and X.-C. Zhao, "Enhanced sunlight photocatalytic performance of Sn-doped $\mathrm{ZnO}$ for Methylene Blue degradation," Journal of Molecular Catalysis A: Chemical, vol. 335, no. 1-2, pp. 145-150, 2011.

[11] C. Wu, L. Shen, H. Yu, Q. Huang, and Y. C. Zhang, "Synthesis of Sn-doped ZnO nanorods and their photocatalytic properties," Materials Research Bulletin, vol. 46, no. 7, pp. 1107-1112, 2011.

[12] C. Karunakaran, S. Sakthiraadha, P. Gomathisankar, and P. Vinayagamoorthy, "The enhanced photocatalytic and bactericidal activities of carbon microsphere-assisted solvothermally synthesized cocoon-shaped $\mathrm{Sn}^{4+}$-doped $\mathrm{ZnO}$ nanoparticles," Dalton Transactions, vol. 42, no. 38, pp. 13855-13865, 2013.

[13] S. A. Ansari, M. M. Khan, M. O. Ansari, J. Lee, and M. H. Cho, "Biogenic synthesis, photocatalytic, and photoelectrochemical performance of Ag-ZnO nanocomposite," Journal of Physical Chemistry C, vol. 117, no. 51, pp. 27023-27030, 2013.

[14] H. R. Jafry, M. V. Liga, Q. Li, and A. R. Barron, "Simple route to enhanced photocatalytic activity of P25 titanium dioxide 
nanoparticles by silica addition," Environmental Science and Technology, vol. 45, no. 4, pp. 1563-1568, 2011.

[15] G. Li, L. Wu, F. Li, P. Xu, D. Zhang, and H. Li, "Photoelectrocatalytic degradation of organic pollutants via a CdS quantum dots enhanced $\mathrm{TiO}_{2}$ nanotube array electrode under visible light irradiation," Nanoscale, vol. 5, no. 5, pp. 2118-2125, 2013.

[16] H. Li, Z. Chen, C. K. Tsang et al., "Electrochemical doping of anatase $\mathrm{TiO}_{2}$ in organic electrolytes for high-performance supercapacitors and photocatalysts," Journal of Materials Chemistry A, vol. 2, no. 1, pp. 229-236, 2014.

[17] X. Liu, D. Geng, X. Wang et al., "Enhanced photocatalytic activity of $\mathrm{Mo}-001 \mathrm{TiO}_{2}$ core-shell nanoparticles under visible light," Chemical Communications, vol. 46, no. 37, pp. 6956-6958, 2010.

[18] P. Song, X. Y. Zhang, M. X. Sun, X. Cui, and Y. Lin, "Graphene oxide modified $\mathrm{TiO}_{2}$ nanotube arrays: enhanced visible light photoelectrochemical properties," Nanoscale, vol. 4, no. 5, pp. 1800-1804, 2012. 

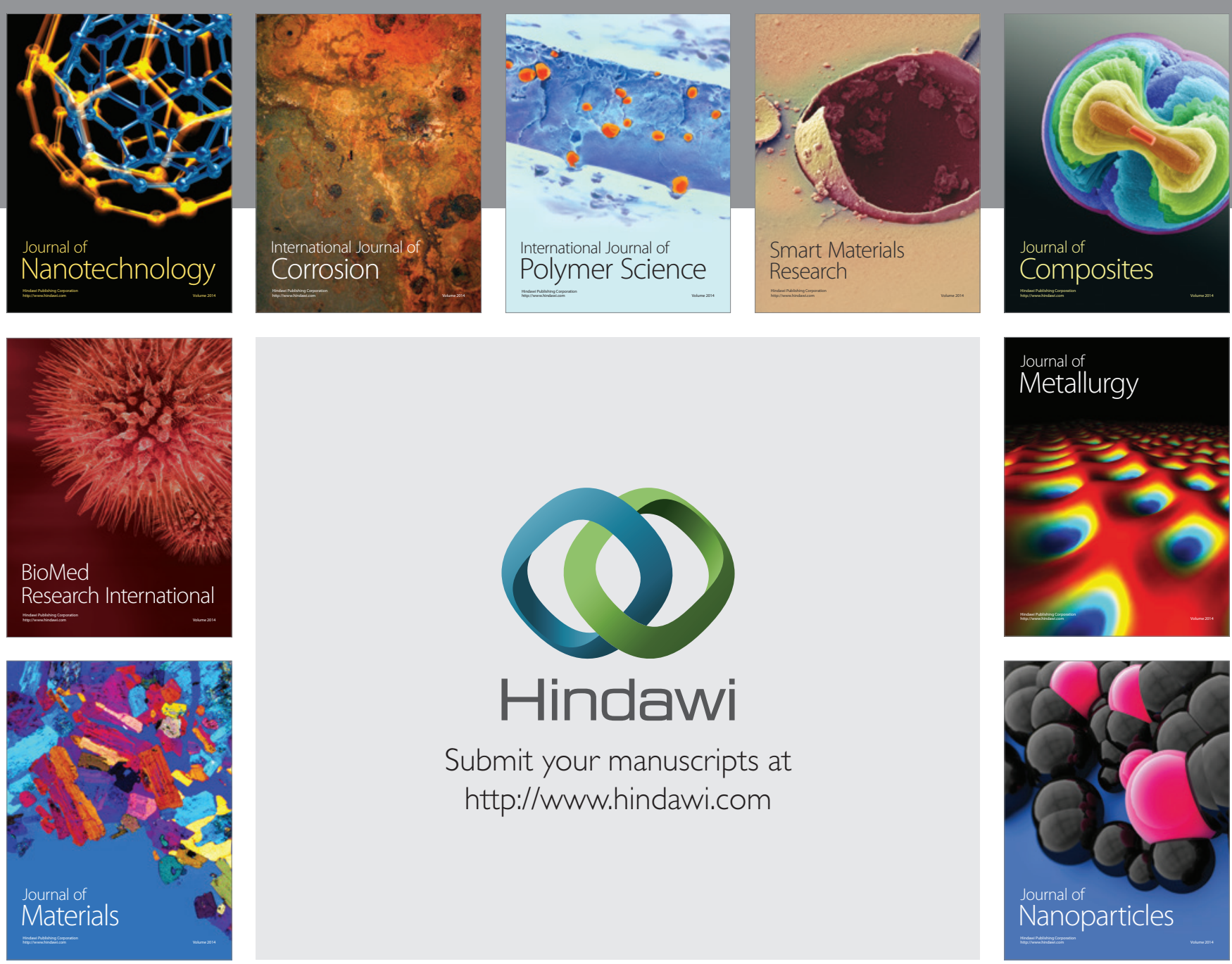

Submit your manuscripts at http://www.hindawi.com
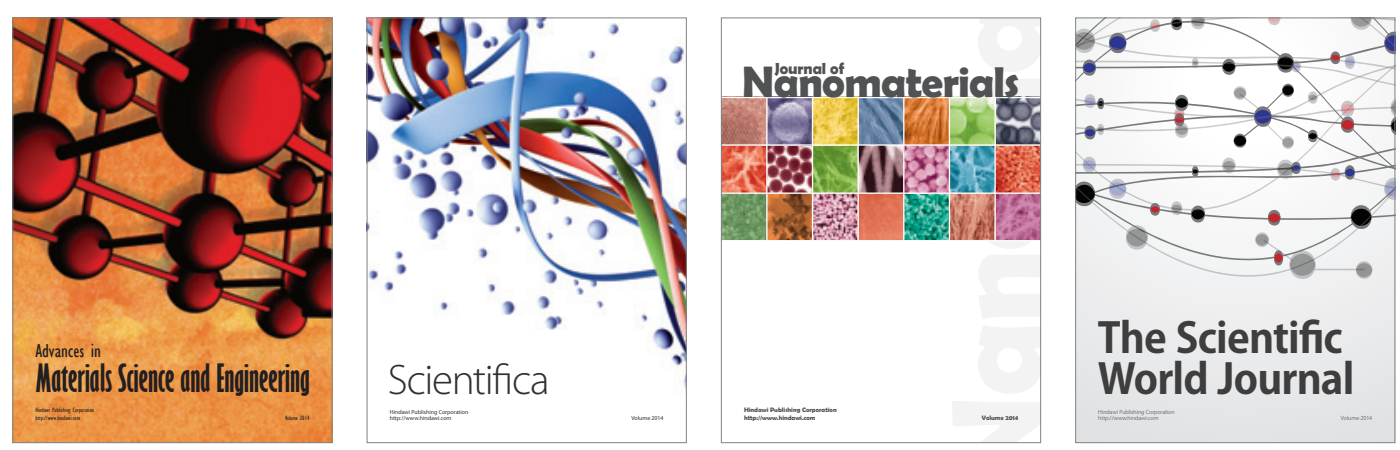

\section{The Scientific World Journal}
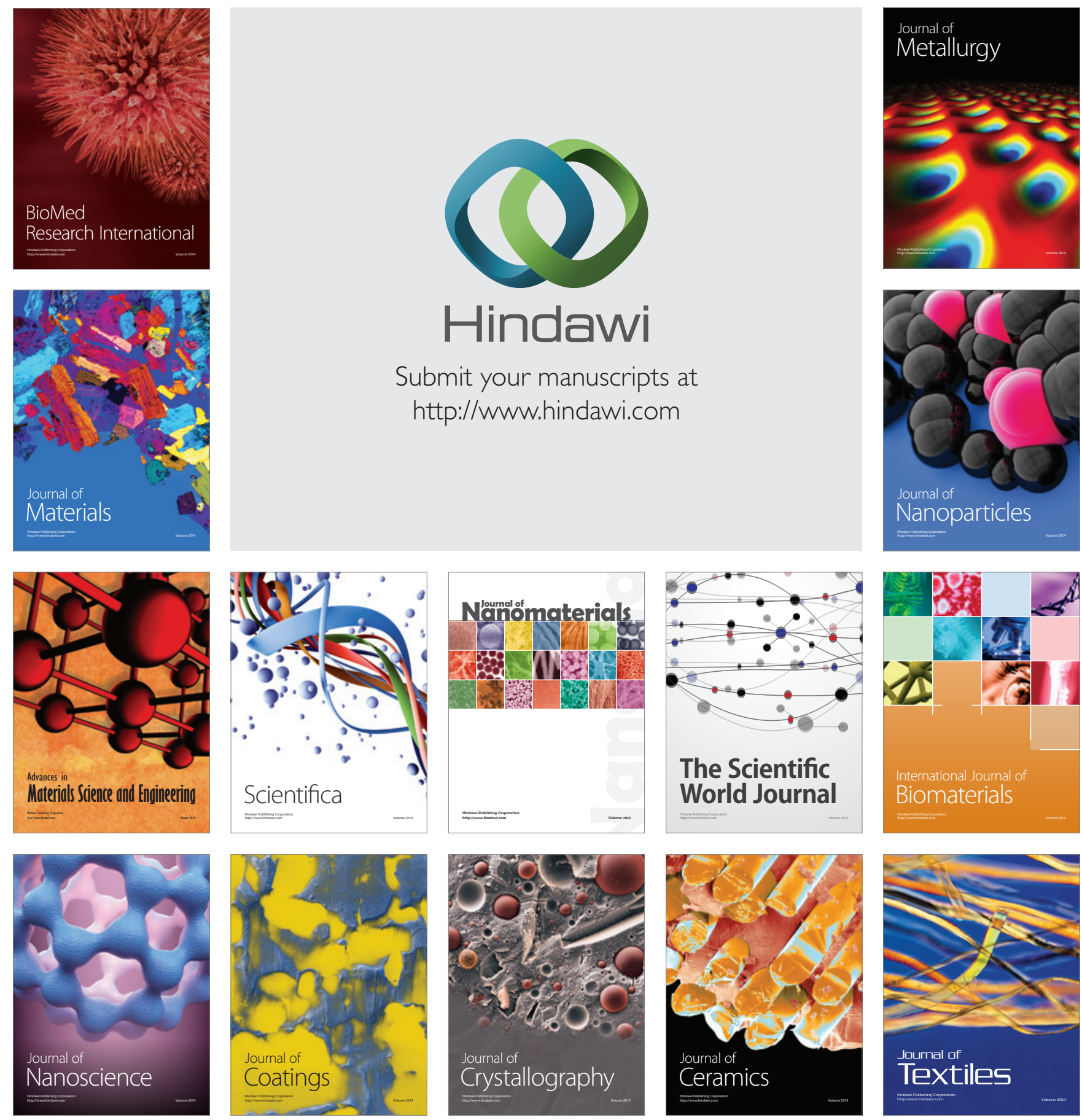